\title{
ANÁLISIS DE PARÁMETROS RESPIRATORIOS EN RELACIÓN AL PROTOCOLO PEFORP EN NIÑOS RESPIRADORES ORALES
}

AUTORES: INSTITUCIÓN: PAIS:
Moya María Paz, Monsalves Nelson, Cisterna Diego

Universidad Autónoma De Chile - Fonoaudiología Temuco Araucanía-Chile

\section{RESUMEN:}

Objetivos: Aplicar el protocolo PEFORP en una muestra chilena de niños con respiración oral, que cursan primer ciclo escolar. Conocer características anatómicas y parámetros respiratorios del grupo evaluado mediante el protocolo PEFORP. Método: Muestra constituida por 30 sujetos, de 6 a 9.11 años que presentan diagnóstico médico de Respiración Oral. La evaluación se realizó mediante aplicación del protocolo PEFORP. Los datos fueron tratados mediante SPSS 21. Resultados: El protocolo PEFORP mostró la capacidad de corroborar el diagnóstico médico de los sujetos con la disfunción, indicando presencia de anteropulsión de cabeza en vista lateral (60\%), inclinación de cabeza en vista anterior y posterior (53\%), inclinación de hombros en vista anterior (73\%), cifosis torácica (60\%) y lordosis lumbar (66\%). Este grupo presenta mayor tendencia de crecimiento dolicofacial (60\%), seguido por mesofacial $(27 \%)$ y braquifacial (13\%); mayor patrón sagital con perfil convexo (61\%). Se aprecian ojeras (80\%), labios entreabiertos (60\%), bermellón reseco (53\%). Labio inferior mayoritariamente con eversión moderada (47\%) y leve (40\%). Se identifica hipertrofia amigdalina grado 3 (47\%), 2 (33\%) y 4 (13\%), así como paladar duro alto (93\%) y ojival (7\%). Conclusiones: Los respiradores orales evaluados presentaron cambios significativos a nivel postural, del desarrollo craneofacial y estructuras fonoarticulatorias. Fue posible confirmar la capacidad de PEFORP para detectar presencia de respiración oral y sus características orofaciales en niños chilenos. Actualmente en Chile no existen instrumentos de evaluación respiratoria estandarizados para el Fonoaudiólogo, que arrojen resultados cuantitativos. Lo anterior muestra la necesidad de contar con una posterior estandarización de PEFORP en nuestro país.

Palabras clave: Respiración, Respiración Oral, Funciones, niños

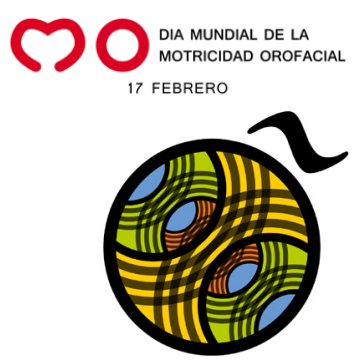

